\title{
A Framework for Valuing Corporate Securities
}

\author{
Jan Ericsson*and Joel Reneby ${ }^{\dagger}$ \\ First version: September 1995 \\ This version: October 1998 \\ Forthcoming in Applied Mathematical Finance
}

\begin{abstract}
We suggest a methodology for valuing corporate securities that allows the straightforward derivation of closed form solutions for complex capital structure scenarios. The tractability of the approach stems from its modularity - we provide a number of intuitive building blocks that are sufficient for valuation in most typical situations. A further advantage of our approach is that it makes economic interpretation far easier than what is typically possible with other approaches such as solving partial differential equations. As examples we consider a corporate coupon bond with discrete payments and debt subject to strategic debt service.
\end{abstract}

${ }^{*}$ Catholic University of Louvain, Department of Economics, Place Montesquieu 3 (Bte 1), B-1348 Louvain-La-Neuve, Belgium. Tel. +32 104735 11, Fax + 32104739 45. Email: ericsson@ires.ucl.ac.be.

${ }^{\dagger}$ Department of Finance, Stockholm School of Economics, Box 6501, S-113 83 Stockholm, Sweden, Tel: + 468 7369143, Fax: + 468 312327, email: finjr@hhs.se. 


\section{Introduction}

With the Black \& Scholes (1973) model, a versatile methodology for the valuation of corporate securities was made available. Their insight was that the payoffs to many instruments on the firm's balance sheet were analogous to those of options. Thus the stock option pricing formula they derived could also be used to price corporate liabilities.

The aim of this paper is to show that some simple ideas related to barrier contracts can be applied to relatively complex scenarios and that closed form expressions for the relevant corporate securities can be obtained with considerable ease. The framework we suggest is flexible enough to accommodate such exigencies as bankruptcy costs, corporate taxes and deviations from the absolute priority rule. Besides ease of implementation, an important advantage of our approach is its transparency. It is more straightforward to interpret components of the derived formulae than if, for example, they had been obtained as solutions to partial differential equations.

The idea of our approach is that many corporate securities can be viewed as portfolios of three basic claims: a down-and-out call option, a down-andout binary option and a unit down-and-in claim. A down-and-out claim is one that expires worthless if the underlying variable hits a given lower boundary prior to the expiration date. A binary option is a contract that yields a unit payoff at the expiration date conditional on the underlying variable exceeding the exercise price. A unit down-and-in claim pays off one currency unit the first time the underlying variable reaches a lower boundary. All these claims have simple valuation formulae.

Using our approach it is straightforward to value finite maturity coupon debt. Under some reasonable restrictions on the default barrier, we can model discrete coupon payments as a portfolio of binary options. Our approach is also readily applicable in situations where there is complex strategic interaction between a firm's claimants. We illustrate this by means of an example.

Our paper is organized as follows: in section 2 we discuss the general contingent claims approach to valuing corporate securities and our basic assumptions. Section 3 provides a synthesis of relevant results from the barrier option pricing literature and presents a general formula for the valuation of corporate securities. Section 4 exemplifies with some applications in order to demonstrate the tractability of our approach. Section 5 provides a concluding discussion.

\section{Preliminaries}

In the following sections we will discuss the links between the economic assumptions and the technical assumptions that we use to model these. In doing so we believe that the limitations and potential of the framework we suggest will become clear. 


\subsection{The state variable, the interest rate and the value of assets}

Throughout this paper, we make the following assumption about the dynamics of the state variable determining the value of the firm's assets.

Assumption 1 The variable determining the liquidation value of the firm's assets at some date $\mathcal{T}$ follows a geometric Brownian motion

$$
\left\{\begin{array}{c}
d v_{t}=\mu v_{t} d t+\sigma v_{t} d W_{t} \\
v_{0}=\underline{v}
\end{array}\right.
$$

where $W_{t}$ with $W_{0}=0$ is a Wiener process under the objective probability measure.

Note that we do not assume that the assets are continuously traded - we only need to assume that they are traded at some date in the future following the maturity of the firm's debt. ${ }^{1}$ However, to use contingent claims methods we need at least one traded security issued by the firm in question - e.g. equity. Furthermore, we need to assume "frictionless" capital markets.

Assumption 2 Capital markets are frictionless for at least some large investors $^{2}$, i.e. there are no transaction costs, assets are perfectly divisible, arbitrage opportunities are ruled out, there are no restrictions on short sales, and borrowing and lending takes place at the risk-free rate. At least one security on the firm's balance sheet is traded.

The risk-free interest rate is a constant $r$. Many recent models incorporate stochastic interest rates. ${ }^{3}$ This is important to the degree that credit risk is correlated with interest rate risk. Although from an economic perspective it appears natural that high interest rates are correlated with harsh conditions for firms and therewith increased default risks, it is not obvious that this effect is significant. At least for high-yield debt, non-systematic credit risk might be by far the most important risk factor. ${ }^{4}$

As a first step and as a benchmark, we choose to retain the assumption of a constant interest rate. We discuss how to relax this assumption in the concluding section.

\footnotetext{
${ }^{1}$ For a thorough discussion of this issue see Ericsson \& Reneby (1998).

2 Merton (1990) (chapter 14) suggests a model in which many investors are unable to trade without transaction costs. Financial intermediaries, on the other hand, may do so by definition. He shows that in such a setting, if intermediation is efficient the products offered by intermediaries will be priced as in an economy without transaction costs.

${ }^{3}$ E.g. Longstaff \& Schwartz (1995), Kim et al. (1993), Saá-Requejo \& Santa-Clara (1997) and Nielsen et al. (1993).

${ }^{4}$ Indeed, to quote Fridson et al. (1997), "empirical investigations have not identified interest rates as an important determinant of default rates on high-yield bonds"; examples are Fridson \& Kenney (1994) and Reilly \& Wright (1994).
} 
Assumption 3 The risk-free interest rate, $r$, is constant. The money market account evolves according to

$$
\left\{\begin{array}{c}
d B_{t}=r B_{t} d t \\
B_{0}=\underline{B}
\end{array}\right.
$$

Consider now the value $\omega_{t}$ of a claim that entitles the holder to $v_{\mathcal{T}}$ at time $\mathcal{T}$. By standard arguments it follows that

$$
\omega_{t}=e^{-r(\mathcal{T}-t)} E^{B}\left[v_{\mathcal{T}}\right]=v_{t} e^{(\mu-\lambda \sigma-r)(\mathcal{T}-t)}
$$

where $E^{B}[\cdot]$ denotes the expectation operator under the probability measure $Q^{B}$, typically referred to as the risk neutral probability measure. ${ }^{5}$ The parameter $\lambda$ may be interpreted as the market price of risk for the operations of the firm.

The contract $\omega_{t}$ may be interpreted as the value of a corresponding all-equity firm or simply the value of assets. The dynamics for $\omega_{t}$ under the objective probability measure are

$$
\left\{\begin{array}{c}
d \omega_{t}=(r+\lambda \sigma) \omega_{t} d t+\sigma \omega_{t} d W_{t} \\
\omega_{0}=\underline{\omega}
\end{array}\right.
$$

The value of assets, that is $\omega_{t}$, is the basis for the pricing of all securities issued by the firm.

If we wish to model a situation where assets generate revenue that is not reinvested one can assume that a fraction $\beta$ of the value of the assets constitute such a net operating cash flow. With this assumption the dynamics of $\omega$ would be

$$
\left\{\begin{array}{c}
d \omega_{t}=(r+\lambda \sigma-\beta) \omega_{t} d t+\sigma \omega_{t} d W_{t} \\
\omega_{0}=\underline{\omega}
\end{array}\right.
$$

The expected growth of the assets is thus the expected return less the generated "free cash flow".

\subsection{Reorganization Trigger}

The firm can default in one of two ways: either if the value of the firm's assets falls below a constant $L$ (the reorganization barrier) at any time prior to maturity of the firm; or if the value of the assets are less than some constant $F$ at debt maturity $T$. This parameter would typically be set equal to the principal $P$ of debt. ${ }^{6}$ The time of default is denoted $\tau$. Formally,

\footnotetext{
${ }^{5}$ The process for $v$ under the probability measure $Q^{B}$ is

$$
\left\{\begin{array}{c}
d v_{t}=(\mu-\lambda \sigma) v_{t} d t+\sigma v_{t} d W_{t}^{B} \\
v_{0}=\underline{v}
\end{array}\right.
$$

Under this probability measure prices normalized by a unit of $B$ are martingales. Note that $v$ does not describe the dynamics of a price variable.

${ }^{6}$ This is the case of Merton (1974) and many subsequent models. However if there is bargaining about the proceeds at maturity (as in Anderson \& Sundaresan (1996)), then this may not be the case.
} 
Assumption 4 Default occurs if

$$
\begin{aligned}
& \omega_{s} \leq L, \text { for some } s \leqslant T \\
& \text { or } \\
& \omega_{T}<F
\end{aligned}
$$

Naturally if one wishes to model a stationary (perpetual) capital structure, as in Black \& Cox (1976) or Leland (1994), the second condition becomes redundant. This is also the case if $L \geq F$.

There are several ways to interpret, and determine, the level of the reorganization barrier. One is to relate it to the total amount of nominal debt. In many countries, corporate law states that financial distress occurs when the value of the firm's assets reaches some lower level, usually related to the total nominal value of outstanding debt. Apart from this judicial view, there are several economic justifications. One is to view the barrier as the level of asset value that is necessary for the firm to retain sufficient credibility to continue its operations or where, due to some covenant, it voluntarily files for bankruptcy. ${ }^{7}$ Another is to think of the barrier as the asset value at which it is no longer possible to honour the payments, be it by selling assets or issuing new securities.

A second approach is based on the supposition that equity holders are too small and scattered to contribute funds to satisfy creditors and avoid a reorganization situation. Thus, assuming that internally generated funds are the only means to service debt (with continuous coupon $C$ ), the firm is solvent as long as internally generated funds exceed the current coupon, i.e. as long as $\beta \omega_{t} d t \geq C d t .{ }^{8}$ Accordingly, we obtain the reorganization barrier $L \equiv \frac{C}{\beta}$.

A third alternative for the reorganization barrier is the level of asset value at which equity holders are no longer willing to contribute funds to stave off financial distress. This choice of barrier is the lowest possible since a lower equity value is not consistent with limited liability. Using this alternative, the barrier is endogenously determined within the model. This approach is considered in section 4.2 .

Finally, many authors have suggested that strategic considerations are important determinants of financial distress. The barrier $L$ could be modelled as the outcome of a game played between debtors and creditors over the assets of the reorganized firm as long as this game is set in a time homogeneous setting. ${ }^{9}$ As we will show below one can allow for several barriers defining regime shifts prior to default. Examples of models that could be accommodated are Mella-Barral \& Perraudin (1997) and the perpetual debt version of Anderson \& Sundaresan (1996) discussed in Anderson et al. (1996).

\footnotetext{
${ }^{7}$ See for example Black \& Cox (1976) and Leland (1994).

${ }^{8}$ This approach has been used by Kim et al. (1993) and Anderson \& Sundaresan (1996).

${ }^{9}$ This guarantees that the barrier is a constant or at most an exponential function of time.
} 


\subsection{Reorganization Payoff}

In reorganization the value of the assets, net of some random reorganization cost, is distributed to claimants. We allow for violations of absolute priority and thus equity holders can be expected to extract some value in default. The term reorganization encompasses such "mild" forms of financial distress as a write-down of the claims of some securities, a resupply of capital and changes in priority, but also downright bankruptcies. The costs of reorganization (denoted $k_{\tau}$ ) consist of, for example, losses due to suspended deliveries by cautious suppliers and the ex post costs of over- or under-investment incentives. The payoff to claimants in reorganization may be in the form of cash or new securities.

We use $\varphi_{\tau}$ to denote the random fraction of asset value net of default costs $\left(\omega_{\tau}-k_{\tau}\right)$ paid out to a particular set of claimants. ${ }^{10}$ If the security is a debt contract, the fraction $\frac{\varphi_{\tau}^{D} \cdot\left(\omega_{\tau}-k_{\tau}\right)}{P}$ measures the recovery rate. The fraction $\frac{\varphi_{\tau}^{E}}{\varphi_{\tau}^{E}+\varphi_{\tau}^{D}}$ quantifies violations of the absolute priority rule. We assume that the distributions of these payoff fractions are independent of time. This hypothesis is supported by Altman \& Kishore (1996), who find that the time to default from a bond's original date of issuance is unrelated with the recovery rate.

Assumption 5 The random fractions of the value of assets distributed to claimants in reorganization are independent of time and the level of asset value.

\section{Valuation}

\subsection{Basic Claims}

The valuation method exploits the fact that contracted payoffs to most of the company's securities can be expressed as combinations of three building blocks: the down-and-out call option, the down-and-out heaviside and a down-and-in claim. Assuming the absence of arbitrage, two claims with identical payoff structures must have the same price. Hence, to value a corporate security, one simply mimics the contracted payoffs of that security with those of the three building blocks.

To formalize the idea of pricing by replicating payoffs, we first need to define the payoff functions, $\Phi$, of the building blocks. Recall that $\tau$ denotes the time of default.

Definition 1 The payoff to a call, down-and-out at a barrier L, written on the asset value, with exercise price $F$ and expiration at $T$ is

$$
\Phi\left\{C_{L}\left\{\omega_{T}, T ; F, T\right\}\right\} \equiv\left\{\begin{array}{r}
\omega_{T}-F \text { if } \omega_{T}>F \text { and } \tau \\
0 \text { if } \omega_{T} \leq F \text { or } \tau \leq T
\end{array}\right.
$$

\footnotetext{
${ }^{10}$ The variable $\varphi_{\tau}$ can be thought of, or even modelled as, the outcome of a bargaining game involving the firm's claimants. We assume that $\varphi_{\tau}$ has support $[0,1]$.
} 
Generally, a subscript ${ }_{L}$ denotes that a claim is down-and-out - i.e. that the payoff is contingent on the barrier $L$ not being hit $(\tau \not \leq T)$. A corresponding ordinary call would thus be denoted $C\left\{\omega_{t}, t ; F, T\right\}$. We will also denote with a superscript ${ }^{L}$ that a claim is down-and-in - i.e. that the payoff is contingent on the barrier being hit $(\tau \leq T)$.

Definition 2 The payoff to a heaviside, down-and-out at a barrier L, written on the asset value, with exercise price $F$ and expiration at $T$ is

$$
\Phi\left\{H_{L}\left\{\omega_{t}, T ; F, T\right\}\right\} \equiv\left\{\begin{array}{c}
1 \text { if } \omega_{T}>F \text { and } \tau \not \leq T \\
0 \text { if } \omega_{T} \leq F \text { or } \tau \leq T
\end{array}\right.
$$

Definition 3 The payoff to a unit down-and-in claim with expiration $T$, is

$$
\Phi\left\{G^{L}\left\{\omega_{\tau}, \tau \mid \tau \leq T\right\}\right\} \equiv\left\{\begin{array}{l}
1 \text { if } \tau \leq T \\
0 \text { if } \tau \not \leq T
\end{array}\right.
$$

In the typical situation where $L$ represents a default barrier this claim can be thought of as one that pays off a dollar in the event of default - a "dollar in default" claim. Thus it gives us a quantitative measure of investors' appreciation of the risk of default.

The price formulae for these claims are given in Lemmas 5-7 below. ${ }^{11}$ They all contain probabilities (under different measures) of the asset value $\left(\omega_{T}\right)$ exceeding the exercise price $(F)$ at maturity without having hit the barrier prior to that date $(\tau \not \leq T)$ - in other words the in-the-money probabilities. To clarify this common structure, we first state those probabilities in the following lemma.

We use $Q^{m}\{A\}$ to denote the probability under a general probability measure $Q^{m}$ of event $A$ occurring. In particular, we consider three measures: $Q^{B}$, $Q^{\omega}$ and $Q^{G}$. These are characterized by having the money market account, the value of assets and a perpetual unit down-and-in claim respectively, as numeraires. ${ }^{12}$ In the following lemma, $\phi\{\cdot\}$ denotes the standard normal cumulative distribution function.

Lemma 4 The probabilities of the event

$$
A=\left\{\tau \not \leq T, \omega_{T}>F\right\}
$$

(the in-the-money event) under the probability measures $Q^{m}: m \in\{B, \omega, G\}$ are

$$
Q^{m}\{A\}=\phi\left\{d_{T}^{m}\left\{\frac{\omega_{0}}{F}\right\}\right\}-\left(\frac{\omega_{0}}{L}\right)^{-\frac{2}{\sigma} \cdot \mu_{X}^{m}} \phi\left\{d_{T}^{m}\left\{\frac{L^{2}}{\omega_{0} \cdot F}\right\}\right\}
$$

where

$$
d_{t}^{m}\{x\}=\frac{\ln x}{\sigma \sqrt{t}}+\mu_{X}^{m} \cdot \sqrt{t}
$$

\footnotetext{
${ }^{11}$ Formulae for the prices of the down-and-out call and heaviside in Lemmas 5 and 6 are not new to the literature (see Merton (1973) and for example Björk (1998)).

${ }^{12}$ See ElKaroui et al. (1995) for a discussion on the links between numeraires and probability measures.
} 


$$
\left\{\begin{array}{c}
\mu_{X}^{B}=\frac{r-\beta-\frac{1}{2} \sigma^{2}}{\sigma} \\
\mu_{X}^{\omega}=\mu_{X}^{B}+\sigma \\
\mu_{X}^{G}=\mu_{X}^{B}-\theta \sigma
\end{array}\right.
$$

and

$$
\theta=\frac{\sqrt{\left(\mu_{X}^{B}\right)^{2}+2 r}+\mu_{X}^{B}}{\sigma}
$$

If $F<L$ set $F=L$ in the above expression. ${ }^{13}$

Using this lemma, the pricing equations for the building blocks $C_{L}, H_{L}$ and $G\{\cdot \mid \tau \leq T\}$ can be written down in a convenient form.

Lemma 5 . The price of a down-and-out call (with payoff as in Definition 1) is given by

$$
\begin{aligned}
C_{L}\left\{\omega_{t}, t ; F, T\right\}= & \omega_{t} e^{-\beta(T-t)} \cdot Q^{\omega}\left\{\tau \not \leq T, \omega_{T}>F\right\} \\
& -e^{-r(T-t)} F \cdot Q^{B}\left\{\tau \not \leq T, \omega_{T}>F\right\}
\end{aligned}
$$

with probabilities given by Lemma 4.

The formula is similar in structure to the ordinary Black-Scholes call option formula. When there is no barrier (implying that the condition $\tau \not \leq T$ becomes redundant), the formula simplifies to the Black-Scholes formula. The price of a down-and-out call option was first derived by Merton (1973).

Lemma 6 The price of a down-and-out heaviside (with payoff given by Definition 2) is

$$
H_{L}\left\{\omega_{t}, t ; F, T\right\}=e^{-r(T-t)} \cdot Q^{B}\left\{\tau \not \leq T, \omega_{T}>F\right\}
$$

with probability given by Lemma 4 .

Thus, a heaviside is merely the "second half" of a call option.

Lemma 7 The price of a unit down-and-in claim (with payoff given by Definition 3) is

$$
\begin{aligned}
G^{L}\left\{\omega_{t}, t \mid \tau \leq T\right\}= & G^{L}\left\{\omega_{t} \mid \tau \leq \infty\right\} \cdot\left(1-Q^{G}\left\{\tau \not \leq T, \omega_{T}>L\right\}\right) \\
& \text { with } \\
G^{L}\left\{\omega_{t} \mid \tau \leq \infty\right\}= & \left(\frac{\omega_{t}}{L}\right)^{-\theta}
\end{aligned}
$$

with probability $Q^{G}\{\cdot\}$ as in Lemma 4 .

\footnotetext{
${ }^{13}$ The term $\mu_{X}^{m}$ is equal to the drift of the process $X_{t} \equiv \frac{1}{\sigma} \ln \frac{\omega_{t}}{L}$ under the probability measure $Q^{m}$. It is also equal to the Girsanov kernel used to go from probability measure $Q^{X}$, where the $X$-process is a Wiener process, to the measure $Q^{m}$.
} 
The claim $G^{L}\left\{\omega_{t}, t \mid \tau \leq T\right\}$ gives us the value of receiving one dollar conditional on hitting the barrier $L$ prior to $T$ and thus takes on a value between zero and one. The claim $G^{L}\left\{\omega_{t} \mid \tau \leq \infty\right\}$, which appears as a component of the formula, is the perpetual counterpart of $G^{L}\left\{\omega_{t}, t \mid \tau \leq T\right\}$. Intuitively, the value of the finite claim is reduced by the $\left(Q^{G}-\right)$ probability that the barrier is reached after $T$. As $\omega_{t}$ approaches the barrier, $G^{L}\left\{\omega_{t}, t \mid \tau \leq T\right\}$ tends to one. As the underlying variable tends to infinity the value of this claim approaches zero. This can be seen by noting that $\theta>0$.

Recall that we have assumed that the recovery fraction $\varphi_{\tau}$ of a claim in default is random but time independent. Let

$$
\varphi \equiv E\left[\varphi_{\tau}\right]
$$

Then the expected recovery in default of a claim is worth $\varphi \cdot(L-k) \cdot G^{L}\left(w_{t}, t \mid \tau \leq T\right)$.

The sum of the values of the corporate securities is equal to the value of the firm, $V$. Note that this value does not in general equal the value of assets, $\omega . V$ will depend on the tax deductibility of interest payments and the costliness and likelihood of financial distress; tax deductibility adds to, and financial distress subtracts from firm value so that we may have both $\omega<V$ and $\omega>V$. In the literature, $V$ is often referred to as the value of the levered firm and $\omega$ the value of the unlevered firm.

Having defined the payoff functions and pricing formulae for the building blocks, we can formalize the idea described at the beginning of this section, i.e. that securities can be valued by replicating their payoffs with those of the above basic securities. We let $C S\left\{\omega_{t}, t ; \cdot\right\}$ denote the value of a general basic security as a function of asset value and time.

Proposition 8 A corporate security $C S$ with contracted payments

$$
\Phi\left\{C S\left\{\omega_{t}, t ; \cdot\right\}\right\}=\left\{\begin{array}{c}
\sum_{i} a^{(i)} \Phi\left(C_{L}\left\{\omega_{t}, t ; F_{i}, t_{i}\right\}\right) \\
+ \\
\sum_{i} b^{(i)} \Phi\left(H_{L}\left\{\omega_{t}, t ; F_{i}, t_{i}\right\}\right)
\end{array}\right.
$$

and an expected recovery fraction $\varphi^{C S}$, can be valued as

$$
C S\left\{\omega_{t}, t ; \cdot\right\}=\left\{\begin{array}{c}
\sum_{i} a^{(i)} C_{L}\left\{\omega_{t}, t ; F_{i}, t_{i}\right\} \\
+ \\
\sum_{i} b^{(i)} H_{L}\left\{\omega_{t}, t ; F_{i}, t_{i}\right\} \\
+ \\
\varphi^{C S} \cdot(L-k) \cdot G^{L}\left\{\omega_{t}, t \mid \tau<T\right\}
\end{array}\right.
$$

where "i" is used to index heavisides and options of different exercise prices and maturities and $a^{(i)}$ and $b^{(i)}$ are constants. The summation operator $\sum$ should be understood to encompass integrals when applicable.

The tractability of the analysis thus stems from the ease with which one can obtain closed form expressions for the values of (European) claims on the firm's assets, such as different classes of debt, by simply matching payoffs of standard claims. 


\subsection{Some useful expressions}

When payments to securities occur on a continuous basis, the sums in Proposition 8 become integrals. These integrals can in certain situations be solved analytically. We consider the case when the exercise price is zero, as when modelling for example coupons and dividends

The first claim we consider will be needed when pricing a continuous coupon stream: i.e. a down-and-out continuous stream of unit payments subject to credit risk.

Definition 9 The payoff to a unit stream, down-and-out at a barrier $L$, is

$$
\Phi\left\{U_{L}\left\{\omega_{\tau}, \tau \mid \tau \leq T\right\}\right\} \equiv \int_{t}^{T} \Phi\left\{H_{L}\left\{\omega_{t}, t ; 0, s\right\}\right\} d s
$$

The value of the unit stream, derived in the appendix, is given in the following lemma.

Lemma 10 The value of a unit stream (with payoff as in Definition 9) is given by

$$
U_{L}\left\{\omega_{t}, t ; T\right\}=\frac{1}{r}\left(1-G^{L}\left\{\omega_{t}, t ; \tau \leq T\right\}-H_{L}\left\{\omega_{t}, t ; 0, T\right\}\right)
$$

As the maturity becomes infinite, the expression simplifies to

$$
U_{L}\left\{\omega_{t} ; \infty\right\}=\frac{1}{r}\left(1-G^{L}\left\{\omega_{t} ; \infty\right\}\right)
$$

We see that the value of a risky, finite stream is equal to the value of a risk free, infinite stream $\left(\frac{1}{r}\right)$ less two terms: the first, $G^{L}$, reflecting the discount due to the risk of default, and the second, $H_{L}$, reflecting the discount attributable to the finite maturity.

The second claim is relevant when we are interested in a continuous dividend stream: i.e. a down-and-out continuous stream of asset payments subject to credit risk.

Definition 11 The payoff to an asset stream, down-and-out at a barrier L, is

$$
\Phi\left\{O_{L}\left\{\omega_{\tau}, \tau \mid \tau \leq T\right\}\right\} \equiv \int_{t}^{T} \Phi\left\{C_{L}\left\{\omega_{t}, t ; 0, s\right\}\right\} d s
$$

The value of the asset stream, derived in the appendix, is given in the following lemma.

Lemma 12 The value of a asset stream (with payoff as in Definition 11) is given by

$$
O_{L}\left\{\omega_{t}, t ; T\right\}=\frac{1}{\beta}\left(\omega_{t}-L \cdot G^{L}\left\{\omega_{t}, t ; \tau \leq T\right\}-C_{L}\left\{\omega_{t}, t ; 0, T\right\}\right)
$$

As the maturity becomes infinite, the expression simplifies to

$$
O_{L}\left\{\omega_{t} ; \infty\right\}=\frac{1}{\beta}\left(\omega_{t}-L \cdot G^{L}\left\{\omega_{t} ; \infty\right\}\right)
$$




\section{Examples}

We will now exemplify the proposed framework by studying some concrete models of corporate liabilities. The examples are chosen so as to illustrate the two main advantages of our approach - tractability and transparence.

First we examine the case of a straight non-callable corporate coupon bond. The reason for this choice is not only that it is an important security in its own right but also one for which it has proved hard to find a closed form expression.

We then proceed to show that our methods can be applied in a model where strategic interaction between claimants plays an important role. We have chosen to study the capital structure model of Mella-Barral \& Perraudin (1997) which not only features endogenous default but also multiple regions in which debt service is carried out strategically. This example demonstrates that our method greatly simplifies the interpretation of the components of a formula. This feature is particularly valuable when contingent claims methods are used in an applied corporate finance setting.

\subsection{A Corporate Coupon Bond}

Consider a firm financed with equity and a single issue of corporate coupon debt with principal $P$, maturity $T$ and constant coupon payments of $c P$ due at dates $t_{i}: i=1, \ldots, N$. Let $k$ denote the expected direct and indirect costs of financial distress. We further assume that $\varphi^{E}>0$, i.e. that the absolute priority rule is violated in financial distress.

Denote the value of equity with $E$ and the value of debt with $D$. The market values of the securities add up to the market value of the company: $V=D+E$.

The values of equity and debt will be the sums of the value of their payoffs at maturity (denoted with ${ }^{M}$ ) and the value of their payoffs in the event of a reorganization prior to maturity (denoted with ${ }^{\tau}$ ), and the value of intermediate payments in solvency (denoted with ${ }^{S}$ ). This can be written

$$
\begin{aligned}
& D=D^{M}+D^{\tau}+D^{S} \\
& E=E^{M}+E^{\tau}+E^{S}
\end{aligned}
$$

We start by deriving the value of the individual maturity payments. To facilitate notation we only consider the case $P \geq L \geq k$.

\subsubsection{Value of Payments at Maturity}

Figure 1 illustrates the payoffs at maturity to debt and equity. The solid line delineates the value of equity at maturity as a function of asset value and the dashed line that of debt.

Formally, the payoff to debt at maturity is

$$
\Phi\left(D^{M}\right)=\left\{\begin{array}{cc}
P & \text { if } \omega_{T} \geq P \\
\varphi^{D} \cdot\left(\omega_{T}-k\right) & \text { if } P>\omega_{T} \geq L
\end{array}\right.
$$




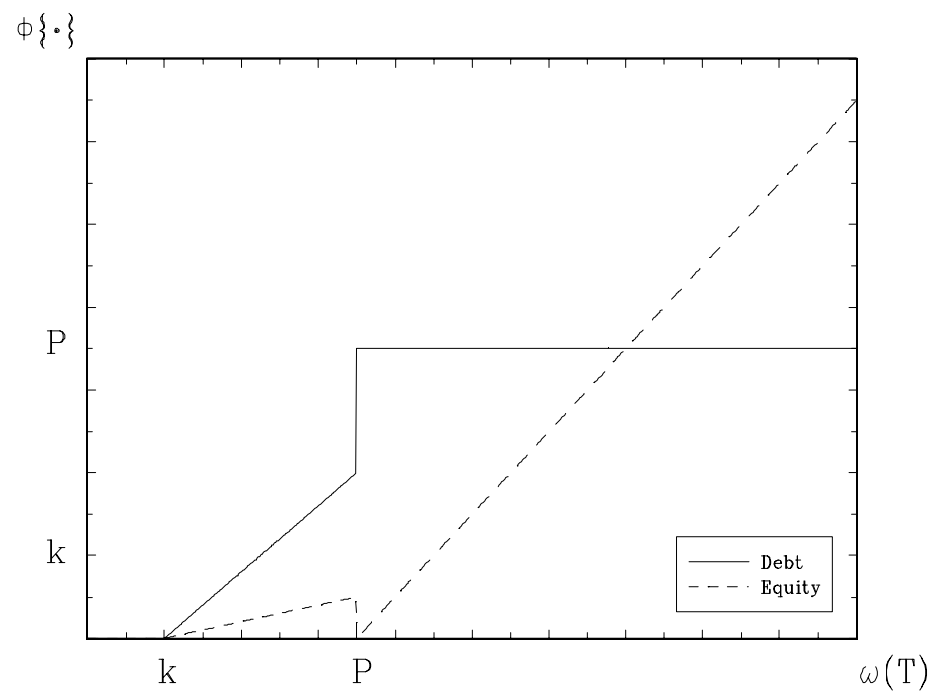

Figure 1: Equity And DeBt. Payoffs to debt and equity at maturity. The solid line represents debt and the dashed line equity. Debt principal is denoted by $P$ and expected default costs by $k$.

$$
\begin{aligned}
= & \varphi^{D} \cdot \Phi\{C(\cdot ; k, T)\}-\varphi^{D} \cdot \Phi\{C(\cdot ; P, T)\} \\
& +\left(\varphi^{D} k+\left(1-\varphi^{D}\right) P\right) \cdot \Phi\{H(\cdot ; P, T)\}
\end{aligned}
$$

Or, verbally, to mimic the payoff to debt you need $\varphi^{D}$ long calls with exercise price $k, \varphi^{D}$ short calls with exercise price $P$ and $\left(\varphi^{D} k+\left(1-\varphi^{D}\right) P\right)$ long heavisides with exercise price $P$. The value of debt's maturity payoffs is therefore simply the sum of these components.

$$
\begin{aligned}
D^{M}(\cdot ; \cdot)= & \varphi^{D} \cdot\left(C_{L}(\cdot ; k, T)-C_{L}(\cdot ; P, T)\right) \\
& +\left(\varphi^{D} k+\left(1-\varphi^{D}\right) P\right) \cdot H_{L}(\cdot ; P, T)
\end{aligned}
$$

Now consider the payoff to equity at maturity: 


$$
\begin{aligned}
\Phi\left\{E^{M}\right\}= & \left\{\begin{array}{cc}
\omega_{T}-P & \text { if } \omega_{T} \geq P \\
\varphi^{E} \cdot\left(\omega_{T}-k\right) & \text { if } P>\omega_{T} \geq L
\end{array}\right. \\
= & \varphi^{E} \cdot \Phi\{C(\cdot ; k, T)\}+\left(1-\varphi^{E}\right) \cdot \Phi\{C(\cdot ; P, T)\} \\
& -\varphi^{E}(P-k) \cdot \Phi\{H(\cdot ; P, T)\}
\end{aligned}
$$

The payoff to equity in this case is equal to the payoff from $\varphi^{E}$ calls with exercise price $k$ and $\left(1-\varphi^{E}\right)$ calls with exercise price equal to the debt principal. Therefore, the value of equity can be expressed as

$$
\begin{aligned}
E^{M}(\cdot ; P, T)= & \varphi^{E} \cdot C_{L}(\cdot ; k, T)+\left(1-\varphi^{E}\right) \cdot C_{L}(\cdot ; P, T) \\
& -\varphi^{E}(P-k) \cdot H_{L}(\cdot ; P, T)
\end{aligned}
$$

\subsubsection{Value of Payments in Case of Reorganization Prior to Maturity}

When the firm defaults we know that $\omega_{\tau}=L$. The payoffs to debt and equity are

$$
\begin{aligned}
& \Phi\left\{D^{\tau}\right\}=\varphi_{\tau}^{D} \cdot\left(L-k_{\tau}\right) \\
& \Phi\left\{E^{\tau}\right\}=\varphi_{\tau}^{E} \cdot\left(L-k_{\tau}\right)
\end{aligned}
$$

and can be valued as

$$
\begin{aligned}
D^{\tau}(\cdot ; T) & =E\left[\Phi\left\{D^{\tau}\right\}\right] \cdot G^{L}\left\{\omega_{t}, t \mid \tau<T\right\} \\
& =\varphi^{D} \cdot(L-k) \cdot G^{L}\left\{\omega_{t}, t \mid \tau<T\right\} \\
E^{\tau}(\cdot ; T) & =E\left[\Phi\left\{E^{\tau}\right\}\right] \cdot G^{L}\left\{\omega_{t}, t \mid \tau<T\right\} \\
& =\varphi^{E} \cdot(L-k) \cdot G^{L}\left\{\omega_{t}, t \mid \tau<T\right\}
\end{aligned}
$$

\subsubsection{Value of Coupons}

As explained in section 2.2 Reorganization trigger we assume that default is driven by a barrier or a failure to honour the principal repayment. Limited liability places restrictions on the possible default triggers. We require that the value of equity is positive for all asset values above the barrier. Formally

$$
E(\omega, t ; c, P, L, \cdot)>0, \forall t, \omega>L
$$

A particular coupon $c P$ is paid out to bondholders given no reorganization prior to the payment date $t_{i}$. Hence, each coupon payment is equivalent to $c P$ 
down-and-out heavisides of maturity $t_{i}$. The exercise price equals the barrier $L$. The value of the coupons is consequently

$$
D^{S}(\cdot ; \cdot)=c P \sum_{i=1}^{N} H_{L}\left(\cdot ; L, t_{i}\right)
$$

The coupon payments decrease the value of equity. But since coupons are tax deductible, only a fraction $1-\varkappa$ of the payments (where $\varkappa$ denotes the tax rate) is borne by equity holders. Hence,

$$
E^{S}(\cdot ; \cdot)=-(1-\varkappa) \cdot c P \sum_{i=1}^{N} H_{L}\left(\cdot ; L, t_{i}\right)
$$

\subsubsection{Summary: value of a single straight coupon bond}

Inserting (7), (9) and (11) into (5) yields the value of debt, while inserting (8), (10) and (12) into (6) gives us the value of equity. We thus obtain the following result:

Example 13 Consider a firm with a capital structure consisting of equity and debt with coupon payment $c P$ at dates $t_{i}$ for $i=1 \ldots N$ and principal repayment of $P$ at $T>t_{N}$. The values of debt, equity, reorganization costs and tax shield are then given by

$$
\begin{array}{r}
D(\omega, t ; \cdot)=\left\{\begin{array}{r}
\varphi^{D} \cdot\left(C_{L}(\cdot ; k, T)-C_{L}(\cdot ; P, T)\right)+k \cdot H_{L}(\cdot ; P, T) \\
+\varphi^{D} \cdot(L-k) \cdot G^{L}\left\{\omega_{t}, t \mid \tau<T\right\} \\
+c P \sum_{i=1}^{N} H_{L}\left(\omega, t ; L, t_{i}\right)
\end{array}\right. \\
E(\omega, t ; \cdot)=\varphi^{E} \cdot C_{L}(\cdot ; k, T)+\left(1-\varphi^{E}\right) \cdot C_{L}(\cdot ; P, T)-\varphi^{E}(P-k) \cdot H_{L}(\cdot ; P, T) \\
+\varphi^{E} \cdot(L-k) \cdot G\left\{\omega_{t}, t \mid \tau<T\right\} \\
-(1-\varkappa) \cdot c P \sum_{i=1}^{N} H_{L}\left(\omega, t ; L, t_{i}\right)
\end{array}
$$

This formula constitutes an alternative to the compound option approach suggested by Geske (1977). It involves nothing more complicated than onedimensional normal distribution functions. In contrast the Geske (1977) model requires solving high dimensional integrals numerically which is likely to be both time consuming and problematic in terms of precision. ${ }^{14}$ Corporate coupon bond can have up to 30 years to maturity with semiannual coupons, requiring

\footnotetext{
${ }^{14}$ One important situation where computation time and (perhaps more importantly) precision are critical issues is when one uses time series of stock prices to extract information about
} 
the computation of an integral with at least 30 dimensions, which may not be practically implementable. ${ }^{15}$

Whether the compound or barrier option approach is the more suitable and realistic is also an economic issue. If the firm is financed solely by a single issue of debt and if default can occur only when relatively large coupons are due, then Geske's model may be appropriate. If, as would seem more likely, the firm is financed by numerous issues of debt with different maturities and timing of payments, a more reasonable hypothesis may be that the firm on aggregate services debt on a continuous basis. Then the default trigger would be more likely to resemble a constant barrier.

\subsubsection{Different classes of debt}

Incorporating additional layers of debt, for example junior debt, requires only an alteration of the maturity payoff function. Denote the principals of senior and junior debt by $P_{S}$ and $P_{J}$ respectively and by $P=P_{S}+P_{J}$ the total nominal amount due at maturity. Suppose that $P_{S}>P_{J}>L>k$. Then the modified payoff functions are

$$
\begin{aligned}
& \Phi\left\{D_{J}^{M}\right\}=\Phi\left\{C\left(\cdot ; P_{S}+k, T\right)\right\}-\Phi\{C(\cdot ; P, T)\}+k \cdot \Phi\{H(\cdot ; P, T)\} \\
& \Phi\left\{D_{S}^{M}\right\}=\Phi\{C(\cdot ; k, T)\}-\Phi\left\{C\left(\cdot ; P_{S}+k, T\right)\right\}
\end{aligned}
$$

\subsubsection{Complex capital structures}

The assumption of one or two issues of debt constituting the total amount of indebtedness is clearly simplistic in many situations. Suppose we are interested in pricing a particular issue which constitutes a relatively small part of total debt. One approach would be to construct a two step model in which the aggregate debt in the capital structure of the firm is summarized as one perpetual issue of coupon debt. A reasonable assumption in such a time homogeneous setting is that default is triggered only by a barrier. One could then value the particular bond issue as

$$
D(\omega, t ; \cdot)=\left\{\begin{array}{c}
P \cdot H_{L}(\omega, t ; L, T) \\
+\varphi^{D} \cdot G^{L}\left\{\omega_{t}, t \mid \tau<T\right\} \\
+c P \sum_{i=1}^{N} H_{L}\left(\omega, t ; L, t_{i}\right)
\end{array}\right.
$$

the underlying state variable process (using for example the Maximum likelihood method suggested by Duan (1994) and studied by Ericsson \& Reneby (1997)). Such a task requires the (typically numerical) inversion of the implicit equity formula several times for each observation of the stock price. If the price of equity itself has to be solved for numerically then this will add considerably to the computational complexity.

${ }^{15}$ Geske (1977) discusses a dimensionality reduction technique which may halve the number of dimensions if payments are equally spaced. However Genz (1992) shows that commonly used algorithms are unlikely to be practical for dimensions greater than 6 and suggests an alternative approach for dimensions up to 10 . 
The difference between this expression and the one derived above is the absence of any option feature at maturity. As the principal of the debt contract is small relative to total nominal debt it is unlikely to trigger default.

\subsection{Strategic debt service}

We now turn to the strategic debt service model of Mella-Barral \& Perraudin (1997). Consider a firm in a risk neutral economy whose output price $p_{t}$, is assumed to follow a geometric Brownian motion.

$$
d p_{t}=\mu p_{t} d t+\sigma p_{t} d W_{t}
$$

The wage associated with producing one unit is a constant $w$.

The firm is financed with equity and one issue of perpetual debt with coupon $c$. In some instances, when the price is lower than $\bar{p}_{s}$, equity holders will find it optimal to service debt strategically; i.e. not to pay the full coupon. Debtholders will accept the lower-than-contracted coupon if they would gain even less by exercising their right of taking over the firm - either for purposes of running the firm themselves or selling the assets for their scrap value, $\gamma$. Eventually, if the price drops sufficiently, equity holders will find it optimal to liquidate the firm. This happens at price level $\bar{p}_{c}$ (for $c$ losure). Both $\bar{p}_{s}$ (for $s$ trategic) and $\bar{p}_{c}$ are determined endogenously.

The intuition for the debt service chosen by equity holders is the following: when the output price is sufficiently high there is no strategic debt service as it would be profitable for creditors to take over the now prosperous firm. For lower prices (less than $\bar{p}_{s}$ ), strategic debt service begins: debtholders are offered a coupon which leaves them slightly better off than if they were to claim their right to take over the firm and run it themselves. The reason is that debtholders are less able managers than the incumbents. This is formalized by letting the (effective) output price fall (to $\xi p_{t}: \xi<1$ ). The coupon that leaves debtholders indifferent between taking over the firm and accepting the lower coupon must be equal to $\xi p_{t}-w$ since that is the operating income they would get each instant if they ran the firm themselves. Moreover, if debtholders were to run the firm, they would choose to liquidate the firm if the output price were to drop below $\bar{p}_{x} \cdot{ }^{16}$ This means that when the price is lower then $\bar{p}_{x}$, debtholders no longer have the outside option to run the firm themselves. Consequently, equity holders do not need to feed debtholders $\xi p_{t}-w$ when the price is lower than $\bar{p}_{x}$; a continuous flow of $r \gamma$ will suffice to dissuade them from forcing bankruptcy. ${ }^{17}$

The question at hand is to find an expression for the value of debt, $D\{p\}$. There are (at least) two approaches to this task. Mella-Barral \& Perraudin

\footnotetext{
${ }^{16}$ This level is higher than the corresponding level when equity holders manage the firm $\left(\bar{p}_{c}\right)$ since the debt holders selling price is lower. The relation between the different price level triggers are thus the following: $\bar{p}_{s}>\bar{p}_{x}>\bar{p}_{c}$.

${ }^{17} \mathrm{~A}$ continuous flow of $r \gamma$ is worth $\gamma$ in a risk neutral world.
} 
(1997) specify and solve partial differential equations with appropriate boundary conditions. A drawback of this approach is that it can be difficult to economically interpret the various components of the obtained formula. This in turn may hamper error-trapping and reduce the amount of information that can be extracted from the model.

Consider instead tackling the described valuation problem with the approach suggested in this paper.

\subsubsection{The value of the firm}

Assuming for now that $\bar{p}_{c}$ is fixed, the value of the firm $(V)$ is equal to the value of the output price stream less the wages paid, as long as the firm is operational, plus the scrap value conditional on closure. Applying lemmas 5-7 and their extensions in section 3.2 we immediately find that the value of the firm is equal to

$$
\begin{aligned}
V\left\{p_{t} ; \bar{p}_{c}\right\}= & O_{\bar{p}_{c}}\left\{p_{t} ; \infty\right\} \\
& -w \cdot U_{\bar{p}_{c}}\left\{p_{t} ; \infty\right\} \\
& +\gamma \cdot G^{\bar{p}_{c}}\left\{p_{t} \mid \tau \leq \infty\right\}
\end{aligned}
$$

This is the value of an infinite income stream $\left(p_{t}\right)$ less the cost of an infinite wage cost stream $(w)$ (both conditional on no liquidation), plus value of receiving the value of the assets $(\gamma)$ in the event of a liquidation.

\subsubsection{The value of debt}

Next we turn to the value of debt (the price level at which strategic debt service is initiated $\left(\bar{p}_{s}\right)$ is determined later ${ }^{18}$ - for the time being, consider it fixed). When the price is high enough for strategic debt service not to be profitable creditors receive a coupon stream $c$. This stream is worth

$$
c \cdot U_{\bar{p}_{s}}\left\{p_{t} ; \infty\right\}=\frac{c}{r} \cdot\left(1-G^{\bar{p}_{s}}\left\{p_{t} \mid \tau \leq \infty\right\}\right)
$$

At the point where management decide to begin to service debt strategically, debt is worth $V\left\{\xi \bar{p}_{s} ; \bar{p}_{x}\right\}$ as shareholders keep creditors indifferent between taking over the firm and accepting the reduced coupon. Since $G^{\bar{p}_{s}}\left\{p_{t} \mid \tau \leq \infty\right\}$ captures the value of receiving one dollar when strategic debt begins, the value of this component is simply

$$
V\left\{\xi \bar{p}_{s} ; \bar{p}_{x}\right\} \cdot G^{\bar{p}_{s}}\left\{p_{t} \mid \tau \leq \infty\right\}
$$

\footnotetext{
${ }^{18}$ The price barriers $\bar{p}_{s}, \bar{p}_{x}$ and $\bar{p}_{c}$ are determined by maximizing the value of equity, debt and the firm with respect to the particular barrier.
} 
The intuition is that debtholders receive $c$ as long as $p_{t}>\bar{p}_{s}$ and gets $W\left\{\xi \bar{p}_{s}\right\}$ when $p_{t}$ hits $\bar{p}_{s}$. In summary, the value of debt in the different output price regions is simply given by

$D\left\{p_{t}\right\}= \begin{cases}\frac{c}{r} \cdot\left(1-G^{\bar{p}_{s}}\left\{p_{t} \mid \tau \leq \infty\right\}\right)+V\left\{\xi \bar{p}_{s} ; \bar{p}_{x}\right\} \cdot G^{\bar{p}_{s}}\left\{p_{t} \mid \tau \leq \infty\right\} & p_{t}>\bar{p}_{s} \\ V\left\{\xi p_{t} ; \bar{p}_{x}\right\} & \bar{p}_{s} \geq p_{t}>\bar{p}_{x} \\ \gamma & \bar{p}_{x} \geq p_{t} \geq \bar{p}_{c}\end{cases}$

The interpretations of the above three lines are the following.

- When the price is high, the value of debt is equal to a weighted average of risk free debt $\left(\frac{c}{r}\right)$ and the value of debt in case the lower boundary is hit $\left(V\left\{\xi \bar{p}_{s} ; \bar{p}_{x}\right\}\right)$. The weight is the value of a claim yielding unit payoff if the lower boundary is hit (remember this claim takes on a value between zero and one).

- When the price is in the intermediate range, the value of debt is equal to the debtholders' outside option - running the firm themselves.

- When the price is very low, the value of debt is equal to the debtholders' outside option in this case - taking over the firm and selling the assets.

\subsubsection{Comparison}

Consider now the formula for debt in Mella-Barral \& Perraudin (1997). ${ }^{19}$ It is

$$
D\left\{p_{t}\right\}= \begin{cases}\frac{c}{r}+\left(X\left\{\bar{p}_{s}\right\}-\frac{c}{r}\right) \cdot\left(\frac{p_{t}}{\bar{p}_{s}}\right)^{\lambda} & p_{t}>\bar{p}_{s} \\ X\left\{p_{t}\right\} & \bar{p}_{s} \geq p_{t}\end{cases}
$$

with $\lambda$ "the negative root of the quadratic equation $\lambda(\lambda-1) \frac{\sigma^{2}}{2}+\lambda \mu=r$ " and the value of the firm under equity and debt management, respectively, is given by $^{20}$

$$
\begin{aligned}
& W\left\{p_{t}\right\}= \begin{cases}\frac{p_{t}}{r-\mu}-\frac{w}{r}+\left(\gamma-\frac{\bar{p}_{c}}{r-\mu}+\frac{w}{r}\right) \cdot\left(\frac{p_{t}}{\bar{p}_{c}}\right)^{\lambda} & p_{t} \geq \bar{p}_{c}\end{cases} \\
& X\left\{p_{t}\right\}= \begin{cases}\frac{\xi p_{t}}{r-\mu}-\frac{w}{r}+\left(\gamma-\frac{\xi \bar{p}_{x}}{r-\mu}+\frac{w}{r}\right) \cdot\left(\frac{p_{t}}{\bar{p}_{x}}\right)^{\lambda} & p_{t} \geq \bar{p}_{x} \\
\gamma & \bar{p}_{x} \geq p_{t}\end{cases}
\end{aligned}
$$

The trigger levels $\left(\bar{p}_{c}, \bar{p}_{x}, \bar{p}_{s}\right)$ are obtained together with the above formulae when solving the partial differential equations.

In our opinion equations (13) and (14) are likely to provide more intuition than (15) and (16). The former equations express the value of securities as a sum

\footnotetext{
${ }^{19}$ Of course, the two formulae are identical. They are just expressed differently as a result of the solution techniques.

${ }^{20}$ Note that the firm value formulae can not be expressed as a single formula, dependent on the price and the barrier only, in this case.
} 
of easily identifiable sub-claims. For example, it is not immediately apparent from (15) that the term $\left(\frac{p_{t}}{\bar{p}_{s}}\right)^{\lambda}$ corresponds to a "dollar-in-boundary" claim (note that $\lambda=-\theta$ ) and thus quantifies the risk of strategic debt service. Note also that deriving the formulae by replicating payoffs requires little more than a basic knowledge of differentiation.

\section{Concluding Remarks}

In this paper we have suggested a flexible approach to derive closed form pricing formulae for corporate securities using a limited number of intuitive building blocks. We argue that our framework not only simplifies the pricing of corporate capital structures but also renders the obtained expressions particularly easy to interpret.

Incorporating e.g. interest rate risk or a non-constant asset volatility can be done without altering the main idea of the presented framework. The structure of the pricing formulae in section 3 would be retained. Without restrictive assumptions in other respects, the main consequence would be the likely loss of a closed form solution for the probabilities. ${ }^{21}$

\footnotetext{
${ }^{21}$ For example Nielsen et al. (1993) obtain an analytic solution incorporating stochastic interest rates for the special case where default is triggered only by the barrier, i.e. they derive the probability $Q^{m}(\tau \nless T)$. Moreover they need to assume that the barrier is random and equal to a fraction of a credit risk free bond. An alternative approach would be to use the numerical scheme used by Longstaff \& Schwartz (1995) in a similar setting.
} 


\section{References}

Altman, E. I. \& Kishore, V. M. (1996), 'Almost everything you wanted to know about recoveries on defaulted bonds', Financial Analysts Journal pp. 57-64.

Anderson, R. \& Sundaresan, S. (1996), 'Design and valuation of debt contracts', Review of Financial Studies vol. 9 no. 1 pp. 37-68.

Anderson, R., Sundaresan, S. \& Tychon, P. (1996), 'Strategic analysis of contingent claims', European Economic Review 40, 871-881.

Björk, T. (1998), Arbitrage Theory in Continuous Time, Oxford University Press.

Black, F. \& Cox, J. C. (1976), 'Valuing corporate securities: Some effects of bond indenture conditions', The Journal of Finance .

Black, F. \& Scholes, M. (1973), 'The pricing of options and corporate securities', Journal of Political Economy pp. 637-653.

Duan, J.-C. (1994), 'Maximum likelihood estimation using price data of the derivative contract', Mathematical Finance Vol 4. No. 2 April pp. 155-167.

ElKaroui, N., Geman, H. \& Rochet, J.-C. (1995), 'Changes of numeraire, changes of probability measure and option pricing', Journal of Applied Probability 32 pp. $443-458$.

Ericsson, J. \& Reneby, J. (1997), 'Implementing firm value based pricing models', Stockholm School of Economics Finance Working paper.

Ericsson, J. \& Reneby, J. (1998), 'On the tradeability of firms' assets', Working Paper.

Fridson, M. S., Garman, M. C. \& Wu, S. (1997), 'Real interest rates and the default rate on High-Yield bonds', The Journal of Fixed Income pp. 29-34.

Fridson, M. S. \& Kenney, J. F. (1994), 'How do changes in yield affect quality spreads?', Extra Credit pp. 4-13. Published by Merrill Lynch Capital Markets.

Genz, A. (1992), 'Numerical computation of multivariate normal probabilities', Journal of Computational and Graphical Statistics 1, 141-149.

Geske, R. (1977), 'The valuation of corporate securities as compound options', Journal of Financial and Quantitative Analysis pp. 541-552.

Harrison, J. (1985), Brownian Motion and Stochastic Flow Systems, John Wiley and Sons.

Kim, I., Ramaswamy, K. \& Sundaresan, S. (1993), 'Does default risk in coupons affect the valuation of corporate bonds?: A contingent claims model', Financial Management, Special Issue on Financial Distress . 
Leland, H. (1994), 'Risky debt, bond covenants and optimal capital structure', The Journal of Finance 49. pp. 1213-1252.

Longstaff, F. A. \& Schwartz, E. S. (1995), 'A simple approach to valuing risky fixed and floating rate debt', The Journal of Finance pp. 789-819.

Mella-Barral, P. \& Perraudin, W. (1997), 'Strategic debt service', Journal of Finance 52 (2), 531-556.

Merton, R. C. (1973), 'The theory of rational option pricing', Bell Journal of Economics and Management Science Vol. 4, No. 1.

Merton, R. C. (1974), 'On the pricing of corporate debt: The risk structure of interest rates', Journal of Finance 29, 449-4790.

Merton, R. C. (1990), Continuous-Time Finance, Blackwell Publishers.

Nielsen, L. T., Saa-Requejo, J. \& Santa-Clara, P. (1993), 'Default risk and interest rate risk: The term structure of defualt spreads', Working paper INSEAD .

Reilly, F. K. \& Wright, D. J. (1994), 'An analysis of High-Yield bond benchmarks', The Journal of Fixed Income pp. 6-25.

Saá-Requejo, J. \& Santa-Clara, P. (1997), 'Bond pricing with default risk', Working paper. 


\section{Appendix}

We use the following additional notation:

- Define the default process

$$
X_{t} \equiv \frac{1}{\sigma} \ln \frac{\omega_{t}}{L}
$$

taking the value zero in default.

- Define $\mu_{X}^{m}$ as the drift of the default process under the general probability measure $Q^{m}$. It is also equal to the Girsanov kernel used to go from probability measure $Q^{X}$, where the $X$-process is a Wiener process, to the measure $Q^{m}$.

Thus

$$
d X_{t}=\mu_{X}^{m} d t+d W^{m}
$$

The term $\mu_{X}^{m}$ is equal to the drift of the process $X_{t} \equiv \frac{1}{\sigma} \ln \frac{\omega_{t}}{L}$ under the probability measure $Q^{m}$.

- The first passage time density at $s$ of the default process to zero under the probability measure $Q^{m}$ is (see e.g. Harrison (1985))

$$
f^{m}\left(X_{t} ; s\right) \equiv \frac{X_{t}}{\sqrt{2 \pi(s-t)^{3}}} e^{-\frac{1}{2}\left(\frac{X_{t}+\mu_{X}^{m}(s-t)}{\sqrt{s-t}}\right)}
$$

- The indicator function $I_{\{E\}}$ has the value unity if the event $E$ is true, and zero otherwise.

Below, we will frequently need to integrate the density function over time and the following lemmas will be useful in that respect.

Lemma 14 The solution to

$$
\int_{t}^{T} e^{-\rho(s-t)} \cdot f^{n}\left(X_{t} ; s\right) d s
$$

is

$$
e^{\left(\mu_{X}^{m}-\mu_{X}^{n}\right) X_{0}} \times\left(1-Q^{m}\{\tau \not \leq T\}\right)
$$

where

$$
\mu_{X}^{m}=\sqrt{\left(\mu_{X}^{n}\right)^{2}+2 \rho}
$$

This result follows from first completing the square for $e^{-\rho(s-t)} \cdot f^{n}\left(X_{t} ; s\right)$ which yields a new density function $f^{m}\left(X_{t} ; s\right)$ characterized by $\mu_{X}^{m}=\sqrt{\left(\mu_{X}^{n}\right)^{2}+2 \rho}$. 
Then remember that the point mass for the first passage time is given by (see e.g. Björk (1998))

$$
\begin{aligned}
Q^{m}\{\tau \leq T\} & =\int_{t}^{T} f^{m}\left(X_{t} ; s\right) d s \\
& =N\left\{\frac{-X_{0}-\mu_{X}^{m}(T-t)}{\sqrt{T-t}}\right\}+e^{-2 \mu_{X}^{m} X_{0}} N\left\{\frac{-X_{0}+\mu_{X}^{m}(T-t)}{\sqrt{T-t}}\right\}
\end{aligned}
$$

Lemma 15 The following expressions are equivalent:

$$
e^{\left(\mu_{X}^{m}-\mu_{X}^{n}\right) X_{0}} \times\left(1-Q^{m}\{\tau \not \leq T\}\right)
$$

and

$$
e^{\left(\mu_{X}^{m^{\prime}}-\mu_{X}^{n}\right) X_{0}} \times\left(1-Q^{m^{\prime}}\{\tau \not \leq T\}\right)
$$

with

$$
\mu_{X}^{m^{\prime}}=-\mu_{X}^{m}
$$

\subsection{The finite dollar-in-boundary claim}

This claim pays off one unit of currency if the boundary is hit prior to $T$. Thus

$$
\begin{aligned}
G^{L}\left\{\omega_{t}, t ; \tau \leq T\right\} & =E^{B}\left[e^{-r(\tau-t)} \cdot I_{\{\tau \leq T\}}\right] \\
& =\int_{t}^{T} e^{-r(s-t)} \cdot f^{B}\left(X_{t} ; s\right) d s
\end{aligned}
$$

Using Lemmas 14 and 15 this is found to be

$$
G^{L}\left\{\omega_{t}, t ; \leq T\right\}=e^{\left(\mu_{X}^{G}-\mu_{X}^{B}\right) X_{0}} \times\left(1-Q^{G}\{\tau \not \leq T\}\right)
$$

where

$$
\mu_{X}^{G}=-\sqrt{\left(\mu_{X}^{B}\right)^{2}+2 r}
$$

Noting that $\mu_{X}^{G}-\mu_{X}^{B}=-\theta \sigma$ yields the desired result.

\subsection{The credit risky unit stream}

Receiving one unit of currency per year for $T$ years as a continuous stream is equivalent to a portfolio of heaviside contracts whose maturities span the period $[t, T]$.

$$
\begin{aligned}
U_{L}\left\{\omega_{t}, t ; T\right\} & =\int_{t}^{T} H_{L}\left\{\omega_{t}, t ; 0, s\right\} d s \\
& =\int_{t}^{T} e^{-r(s-t)} Q^{B}\{\tau \not \leq s\} d s
\end{aligned}
$$


Integrating by parts

$$
\begin{aligned}
\int_{t}^{T} e^{-r(s-t)} Q^{B}\{\tau \not \leq s\} d s= & {\left[-\frac{e^{-r(s-t)}}{r} Q^{B}\{\tau \not \leq s\}\right]_{t}^{T} } \\
& -\int_{t}^{T} \frac{e^{-r(s-t)}}{r} f^{B}\left\{\omega_{t}, s\right\} d s
\end{aligned}
$$

The first term is

$$
\begin{aligned}
{\left[-\frac{e^{-r(s-t)}}{r} Q^{B}\{\tau \not \leq s\}\right]_{t}^{T} } & =-\frac{e^{-r(T-t)}}{r} Q^{B}\{\tau \not \leq T\}+\frac{e^{-r(t-t)}}{r} Q^{B}\{\tau \not \leq t\} \\
& =\frac{1}{r}\left(1-e^{-r(T-t)} Q^{B}\{\tau \not \leq T\}\right)
\end{aligned}
$$

where $e^{-r(T-t)} Q^{B}\{\tau \not \leq T\}$ is a heaviside. The second term is equal to $\frac{1}{r}$ dollarin-default claims (see previous subsection). Thus

$$
U_{L}\left\{\omega_{t}, t ; T\right\}=\frac{1}{r}\left(1-H_{L}\left\{\omega_{t}, t ; T\right\}-G^{L}\left\{\omega_{t}, t ; \tau \leq T\right\}\right)
$$

The result for the perpetual claim follows as a limiting case.

\subsection{The credit risky asset value stream}

Receiving the asset value each year for $T$ years as a continuous stream is equivalent to a portfolio of call option contracts, with zero exercise price, whose maturities span the period $[t, T]$.

$$
\begin{aligned}
O_{L}\left\{\omega_{t}, t ; T\right\} & =\int_{t}^{T} C_{L}\left\{\omega_{t}, t ; 0, s\right\} d s \\
& =E^{B}\left[\int_{t}^{T} e^{-r(s-t)} \omega_{s} I_{\{\tau \not s\}} d s\right] \\
& =\int_{t}^{T} e^{-r(s-t)} E^{B}\left[\omega_{s} \cdot I_{\{\tau \not \leq s\}}\right] d s \\
& =\int_{t}^{T} e^{-r(s-t)} E^{B}\left[\omega_{s}\right] \cdot E^{\omega}\left[I_{\{\tau \not \leq s\}}\right] d s \\
& =\int_{t}^{T} e^{-\beta(s-t)} \cdot \omega_{t} \cdot Q^{\omega}\{\tau \not \leq s\} d s
\end{aligned}
$$

Integrating by parts

$$
\begin{aligned}
O_{L}\left\{\omega_{t}, t ; T\right\} & =E^{B}\left[\int_{t}^{T} e^{-r(s-t)} \omega_{s} I_{\{\tau \not \leq s\}} d s\right] \\
& =\omega_{t}\left[-\frac{e^{-\beta(s-t)}}{\beta}\left(1-Q^{\omega}(\tau \leq s)\right)\right]_{t}^{T}-\omega_{t} \int_{t}^{T} \frac{e^{-\beta(s-t)}}{\beta} \cdot f^{\omega}\left(X_{t} ; s\right) d s
\end{aligned}
$$


The first term is

$$
\begin{aligned}
\omega_{t}\left[-\frac{e^{-\beta(s-t)}}{\beta} Q^{\omega}\{\tau \not \leq s\}\right]_{t}^{T} & =-\omega_{t} \frac{e^{-\beta(T-t)}}{\beta} Q^{\omega}\{\tau \not \leq T\}+\omega_{t} \frac{e^{-\beta(t-t)}}{\beta} Q^{\omega}\{\tau \not \leq t\} \\
& =\frac{\omega_{t}}{\beta}\left(1-e^{-\beta(T-t)} Q^{\omega}\{\tau \not \leq T\}\right)
\end{aligned}
$$

where $e^{-\beta(T-t)} \omega_{t} Q^{\omega}\{\tau \not \leq T\}$ is the expression for a call with zero exercise price. To solve for the second term, first note that by square completion it can be shown that

$$
\omega_{t} \int_{t}^{T} e^{-\beta(s-t)} \cdot f^{\omega}\left(X_{t} ; s\right) d s=L \int_{t}^{T} e^{-r(s-t)} \cdot f^{B}\left(X_{t} ; s\right) d s
$$

The right hand side is equal to $L$ dollar-in-default claims of maturity $T$ (see equation (17)). Hence

$$
O_{L}\left\{\omega_{t}, t ; T\right\}=\frac{1}{\beta}\left(\omega_{t}-C_{L}\left\{\omega_{t}, t ; 0, T\right\}-L \cdot G^{L}\left\{\omega_{t}, t ; \tau \leq T\right\}\right)
$$

The result for the perpetual claim follows from taking the limit. 